\title{
DOSSIER
}

\section{Militarización y formaciones armadas en América Latina durante las guerras revolucionarias}

La emergencia de los Estados Nacionales bajo moldes republicanos en Hispanoamérica, fue una experiencia inédita para los hombres y mujeres que desde diversos ángulos se enfrentaron a lo que hoy cierta historiografía denomina acertadamente un "experimento". Sin duda, el modelo adoptado por las élites dirigentes de los territorios recientemente emancipados del imperio hispano durante buena parte del siglo XIX, fueron ensayos, al no existir en ese momento mayores referencias de una forma de organización política entre pueblo y gobernante, salvo buscarlas en el mundo clásico grecolatino y las ciudades Estado del Renacimiento, junto con algunas reflexiones de los teóricos del contractualismo e incluso de pensadores medievales. De hecho, el republicanismo como ideología había conquistado los salones de las Cortes reales de Europa occidental hacia la segunda mitad del siglo XVIII, convirtiéndose en el referente para criticar la corrupción y la venalidad del régimen, pero no proponía el cómo debía ser el gobierno, salvo mirar a la Roma clásica como la encarnación de tales principios ${ }^{1}$. Autores como Hilda Sabato y James Sanders, han señalado este carácter inédito y novedoso, así como también azaroso, que explica en cierta medida las crisis y la falta de legitimidad recurrentes que atravesaron los Estados Latinoamericanos, expresados en golpes de Estado, guerras civiles, cuartelazos, rebeliones, levantamientos armados, entre otras ${ }^{2}$.

1 Gordon S. Wood, "El Legado de Roma y el republicanismo", en: La revolución Angloamericana como revolución, (Bogotá: Ediciones Plural, 2019), 65-100

2 Hilda Sabato, Republics of the new world. The revolutionary political experiment in 19th-century Latin America (Princeton: Princeton University Press, 2018), 27; James E. Sanders, The vanguard of Atlantic world. Creating modernity, nation, and democracy in nineteenth-century Latin America (Durham: Duke Universitu Press, 2014). 
Parte de lo incierto del periodo se debió a la militarización de la sociedad, una de las tantas consecuencias de las llamadas guerras de independencia. El fenómeno identificado con claridad al iniciar la década de los setenta del siglo XX por el historiador argentino Tulio Halperín Donghi (1972), sólo vino a ser tenido en cuenta al iniciar la nueva centuria, cuando una nueva generación de historiadores comenzaron a valorar el papel de la guerra en la configuración del Estado y la cultura política de los países Latinoamericanos durante el siglo XIX ${ }^{3}$.

De esta manera la militarización que permeó estas sociedades decimonónicas, se convirtió una noción capaz de articular y dar sentido a una multiplicidad de fenómenos como los grupos armados, la guerra y otras formas contenciosas que hasta ese momento habían sido tratadas aisladamente que corroboraba el supuesto fracaso de construcción de los Estados. La presencia en el espacio público cotidiano de militares y formaciones castrenses o cuasicastrenses, coadyuvó a modelar los principios republicanos en boga, al exaltar nociones y valores estrechamente asociados al oficio de la guerra o a la guerra en sí misma, que al decir de algunos autores se promovió una "Sociedad Guerrera", y con ello una re-semantización de las palabras provenientes del antiguo Régimen, a las cuales se le otorgaron nuevos significados, modelando de esta manera la forma de percibir los acontecimientos ${ }^{4}$.

En este orden de ideas, uno de los campos historiográficos para indagar la militarización y que tiene hoy un creciente interés es el estudio de los diversos cuerpos armados que pulularon en el paisaje político del siglo XIX. Un coto investigativo que incluye desde los ejércitos republicanos, a las diversas formaciones armadas (milicias nacionales o provinciales, guerrillas, montoneras, partidas de bandoleros, entre otras) las cuales son un rico laboratorio para mirar como las comunidades y pueblos las

3 Tulio Halperin Donghi, Revolución y Guerra. Formación de una élite dirigente en la Argentina criolla (Buenos Aires: Siglo XXI Editores, 2014). Un ejemplo de esta valorización se puede ver en: Marisa Davio, Morir por la Patria. Participación y militarización de los sectores populares en Tucumán, 1812-1854 (Rosario: Protohistoria, 2018).

4 Un trabajo que aborda este asunto es: María Teresa Uribe de Hincapié, Liliana María López Lopera, Las palabras de la guerra. Un estudio sobre las memorias de las guerras civiles en Colombia (Medellín: La Carreta Histórica, 2010) 
vehiculizaron para expresar sus intereses y anhelos. Es decir, cómo éstas organizaciones unas más regulares, otras más colecticias, unas veces dentro u otras veces por fuera de la ley, según los vaivenes políticos, fueron el medio para expresar ideas y proyectos, que en muchos casos eran de carácter local e incluso nacional. Pero también para analizar cómo estas asociaciones expresan lógicas de accionar y estructuras que están atadas a su contexto y cultura, permitiendo ver la forma como se ensambla la estructura social en las asociaciones guerreras.

Por consiguiente, la militarización de las sociedades Latinoamericanas es un tema que lentamente nos está ayudando a mirar de forma diferente fenómenos que hasta hace unos años era explicado en términos negativos. Por ejemplo, las guerras, los caudillos y los diversos conflictos que desgarraron a las sociedades del continente, hoy son analizados desde el complejo proceso de construcción del Estado y la Nación, para observar la construcción de identidades, la politización de los sectores plebeyos y hacer más democrática la participación política, la cual no necesariamente pasaba por las elecciones, la opinión pública y los salones del congreso.

Igualmente, el problema se convierte en una vía heurística para revisitar el siglo XIX y ver la actuación de los grupos armados así como la militarización de las sociedades, como elementos centrales para la comprensión de la cultura política de dicha centuria. Incluso, reconsiderar la idea de orden público y de monopolio legítimo de la violencia en términos weberianos, que hasta hace no muchos años era uno de los paradigmas que guiaba el estudio de la formación de los Estados en nuestra área geográfica, y, por ende, no permitía una mayor comprensión de ciertos fenómenos que se daban en aquellas sociedades, en relación a ciertas prácticas y nociones republicanas como la ciudadanía armada. Todo esto ha permitido replantear el estudio del republicanismo en el continente, y como éste se adaptó a un contexto donde la guerra, el ejército y demás formaciones armadas que en el siglo XIX formaron parte de los entramados sociales de la región ${ }^{5}$.

5 Por ejemplo, en esta línea se pueden leer el trabajo de: Marta Irurozqui, Ciudadanos armados de ley. A propósito de la violencia en Bolivia, 1839-1875, (La Paz: Instituto Francés de Estudios Andinos, 
En síntesis, estudiar la militarización y los cuerpos armados que proliferaron en el siglo XIX, sobre un marco hegemónico republicano, es una de las áreas de investigación que puede ser más fructífera para nuestra nueva historia política, ya que exige hacer análisis micros en relación con el contexto. Es analizar lo local y su conexión provincial o nacional, es ver desde la capilaridad (permítasenos esta expresión biológica) de como se daban los procesos de polinización política de los sectores plebeyos, en este caso al interior de unidad armada ${ }^{6}$.

Los artículos publicados en este dossier se inscriben en este campo de reflexión. Se inicia con el artículo de Nicolás Duffau, quien aborda a partir del sitio de Montevideo (1843-1844), uno de los principales problemas que debieron afrontar las fuerzas regulares: la deserción. Su estudio centrado en la década del cuarenta, le permite a partir de los casos identificados de desertores aproximarse al universo social de cómo estaban constituidas las unidades militares y distanciarse de aquellos relatos nacionales que afirmaban ser unificadas y homogéneas. Contrario a ese ideal, muestra como las compañías estaban conformadas por individuos procedentes de los sectores bajos o plebeyos de la sociedad, muchos de ellos enrolados por ser contraventores de la ley, redundando en cuerpos armados con poca cohesión e identidad frente al bando en el cual estaban reclutados. En este caso, las redes sociales son la base estructural que le permite al autor explicar la sangría de hombres ${ }^{7}$. El artículo de David Fernando Prado y Christian Camilo Valencia, nos introduce en

Editorial Plural, 2018); Carmen McEvoy, Alejandro Rabinovich, Eds. Tiempo de Guerra. Estado, nación y conflicto armado en el Perú, siglos XVII-XIX (Lima: Instituto de Estudios Peruanos, 2018); Juan Ortiz Escamilla, Guerra y gobierno. Los pueblos y la independencia de México, 1808-1825 (México: Colegio de México, Instituto de Investigaciones Dr. José Luis Mora, 2014).

6 Un maravilloso estudio que aborda este asunto es: Raúl Fradkin, La Historia de una montonera. Bandolerismo y caudillismo en Buenos Aires (Buenos Aires: Siglo XXI Editores, 2006). Otro ejemplo es el análisis de la estructuras y nivel organizativo de las montoneras que 1895 derrocaron el régimen de Andrés Avelino Cáceres en Perú, ver: Nils Jacobsen, "La guerra de la coalición Nacional, 18941995: de las guerras civiles de la etapa caudillista a los movimientos de la sociedad civil”, Carmen Mc Evoy, Alejandro Rabinovich Eds. Tiempo de Guerra. Estado..., 441-493; Marie-Danielle Demélas, Nacimiento de la guerra de Guerrillas. El diario de José Santos Vargas (1814-1825) (La Paz: Instituto Francés de Estudios Andinos, Ediciones Plural, 2007).

$7 \quad$ Nicolás Duffau, "Los "hombres funestos". Soldados delincuentes, redes de deserción y guerra política durante los dos primeros años del Sitio Grande de Montevideo (1843-1844)", Historia Caribe Vol. XV No. 36 (Enero-Junio 2020): 21-49. DOI: http://dx.doi.org/10.15648/hc.36.2020.3 
uno de los campos poco atendidos en la historia social de los ejércitos, me refiero al tema del abastecimiento. Sus autores desentrañan para el caso de Popayán la forma cómo la ciudad entre 1808 y 1824, organizó el abasto para los diferentes batallones que se acantonaron o transitaron en la localidad. Describen como la guerra exigió al cabildo poner en práctica una serie de innovaciones para responder a las demandas de alimentos, ropas y vituallas en general, que los hombres en armas de distinto bando les exigían a las autoridades civiles. De esta manera develan los ajustes que debieron hacer las corporaciones de cuño colonial, frente a las novedades que se presentaban en sus sociedades y de paso innovar en prácticas administrativas, que posteriormente se van a convertir en regulares en el nuevo Estado republicano ${ }^{8}$.

Las investigaciones de Gabriela Gresores, Silvia Escanilla Huerta, Marissa Bazán Díaz y Moisés Guzmán Pérez, desde diversas aristas estudian las diversas formaciones armadas que durante o después de las guerras de independencia formaron parte del paisaje político del continente. Sin duda alguna este es uno de los campos más prometedores para los investigadores del fenómeno de la militarización, en tanto aún existe una gran incomprensión de este tipo de fuerzas. Gabriela Gresores analiza un motín de "escuadrones de gauchos" en Jujuy al finalizar las luchas emancipadoras, para mostrarnos el grado de politización que habían sido objeto los sectores populares a consecuencia de la experiencia militar y guerrera, demostrando la capacidad de los hombres provenientes de los mundos bajos rurales en levantar un programa de reivindicaciones políticas, articuladas a la cohesión y a las vivencias en las unidades militares'. Silvia Escanilla, explora la organización de milicias por parte de los pueblos costeros del virreinato del Perú a consecuencia del desembarco del ejército libertador en Pisco en 1820 y la forma autónoma como actuaron; un comportamiento que se repetirá

8 David Fernando Prado Valencia y Christian Camilo Valencia Colina. "Una carga para los pobladores y un desafió para las autoridades: el abastecimiento de los ejércitos en el suroccidente neogranadino durante las guerras de 1808-1824", Historia Caribe Vol. XV No. 36 (Enero-Junio 2020): 51-72. DOI: http://dx.doi.org/10.15648/hc.36.2020.4

9 Gabriela Gresores. "Organización y programa político de los "gauchos" de Jujuy a fines de la Guerra de Independencia”, Historia Caribe Vol. XV No. 36 (Enero-Junio 2020): 73-103. DOI: http:// dx.doi.org/10.15648/hc.36.2020.5 
a lo largo de los diversos conflictos que se suscitaron en las siguientes décadas, que corrobora la capacidad de agencia de los poblados del litoral peruano y la forma como estos cuerpos armados fueron usados por las comunidades para defender sus intereses y constituir una forma de hacer la guerra, poco acorde con las formaciones de ejércitos regulares $^{10}$. Marissa Bazán, presenta un estudio de las montoneras de Huánuco, que en 1812 lograron instalar una junta de gobierno local. El texto describe cómo este repertorio de movilización colectiva, que se volvió una regularidad en el caso peruano hasta finales del siglo XIX, tuvo en el caso de estudio una racionalidad ritual en su accionar, permitiéndole concluir a la autora que su comportamiento no fue caótico, ni desordenada su movilización, más bien estaba articulada a las lógicas comunales y rurales de donde provenían sus miembros ${ }^{11}$. Moisés Guzmán Pérez, estudia una de las guerrillas que emergió en la región del Bajío a consecuencia del levantamiento de septiembre de 1810, desencadenado una insurrección general en el poderoso y rico virreinato de Nueva España. En este caso se centra en la hueste liderada por el padre José Antonio Torres, de quien se explora su perfil y activismo político, para demostrar la importancia que tuvo éste jefe de guerrilla en la región. Además de analizar su formación, estructura, actuación, el tipo de guerra irregular que promovió y los objetivos que los motivaba a la insurgencia ${ }^{12}$.

Finalmente tenemos los estudios de Facundo Roca y Alejandro San Francisco, el primero tiene como objeto mostrarnos cómo el proceso de militarización de la sociedad del Río de la Plata, promovió una nueva forma de entender la muerte y resignificarla dentro de un nuevo marco hegemónico, que exaltó unos principios y valores asociados a la guerra y a la lucha por la patria, muy por el contrario de la muerte barroca del periodo colonial. Su texto, es un ejemplo de cómo el advenimiento del

10 Silvia Escanilla Huerta. "Las milicias locales y la bandolerización de la guerra de independencia en el Perú (1820-1822)”, Historia Caribe Vol. XV No. 36 (Enero-Junio 2020): 105-136. DOI: http:// dx.doi.org/10.15648/hc.36.2020.6

11 Marissa Bazán Díaz. "Montoneras andinas, violencia ritual y saqueos: el caso de los rebeldes de Huánuco (1811-1812)”, Historia Caribe Vol. XV No. 36 (Enero-Junio 2020): 137-167. DOI: http:// dx.doi.org/10.15648/hc.36.2020.7

12 Moisés Guzmán Pérez. "Práctica Bélica En La Revolución Novohispana: La Guerrilla Del Padre José Antonio Torres, 1814-1818”, Historia Caribe Vol. XV No. 36 (Enero-Junio 2020): 169-204. DOI: http://dx.doi.org/10.15648/hc.36.2020.8 
nuevo orden republicano permitió a los hombres y mujeres que vivieron el fenómeno percibir prácticas, rituales y palabras de antaño de otra manera ${ }^{13}$. El segundo, se enfoca en uno de los principales problemas que el republicanismo en el continente se enfrentó, el cual está asociado al lugar que deben tener las fuerzas armadas en el nuevo orden político. En este sentido, su autor muestra la complejidad del tema, de diseñar un andamiaje administrativo, si se nos permite decirlo así, capaz de someter al ejército al dosel constitucional y de sujetar a los oficiales a los poderes civiles. Un asunto del que, si bien existía cierta claridad teórica, se carecía de una experiencia sobre la forma de cómo llevarla a la práctica ${ }^{14}$.

\title{
Luis Ervin Prado Arellano
}

Editor Invitado

Universidad del Cauca (Colombia)

\author{
Alejandro Rabinovich \\ Editor Invitado \\ Consejo Nacional de Investigaciones \\ Científicas y Técnicas - CONICET (Argentina) \\ Universidad Nacional de la Pampa (Argentina)
}

\section{Jorge Conde Calderón}

Editor Invitado

Universidad del Atlántico (Colombia)

http://dx.doi.org/10.15648/hc.36.2020.2

13 Facundo Roca. "La militarización de la muerte: guerra y religión en el Río de la Plata a comienzos del siglo XIX (1806-1820)”, Historia Caribe Vol. XV No. 36 (Enero-Junio 2020): 205-234. DOI: http:// dx.doi.org/10.15648/hc.36.2020.9

14 Alejandro San Francisco. "El ejército y la definición de sus principios constitucionales. Obediencia y no deliberación política en Chile, 1829-1830”, Historia Caribe Vol. XV No. 36 (Enero-Junio 2020): 235-277. DOI: http://dx.doi.org/10.15648/hc.36.2020.10 